\title{
Average Current Mode Control for LLC Series Resonant DC-to-DC Converters
}

\author{
Chang Hee Park ${ }^{*}$, Sung Ho Cho ${ }^{*}$, Jinhaeng Jang ${ }^{* *}$, Syam Kumar Pidaparthy ${ }^{* * *}$, \\ Taeyoung Ahn ${ }^{* * * *}$, and Byungcho Choi ${ }^{\dagger}$ \\ *Department of Electronics Engineering, Hanyang University, Seoul, Korea \\ ${ }^{* *}$ LG Electronics, Pyeongtaek, Korea \\ ${ }^{\dagger * * *}$ School of Electronics Engineering, Kyungpook National University, Daegu, Korea \\ ${ }^{* * * * *}$ Department of Electronics Engineering, Cheongju University, Cheongju, Korea
}

\begin{abstract}
An average current mode control scheme that consistently offers good dynamic performance for LLC series resonant DC-to-DC converters irrespective of the changes in the operational conditions is presented in this paper. The proposed control scheme employs current feedback from the resonant tank circuit through an integrator-type compensation amplifier to improve the dynamic performance and enhance the noise immunity and reliability of the feedback controller. Design guidelines are provided for both current feedback and voltage feedback compensation. The performance of the new control scheme is demonstrated through an experimental $150 \mathrm{~W}$ converter operating with $340 \mathrm{~V}$ to $390 \mathrm{~V}$ input voltage to provide a $24 \mathrm{~V}$ output voltage.
\end{abstract}

Keywords: Average current mode control, Closed-loop performance, Control design, Dynamic analysis, LLC series resonant converters

\section{INTRODUCTION}

LLC series-resonant DC-to-DC converters are traditionally controlled by voltage mode control in which output voltage alone is employed as the feedback signal. As demonstrated in [1-4], the performance of voltage mode control is directly influenced by changes in the operational condition of the converter, thereby making the control scheme inappropriate for practical LLC converters that usually deal with substantial variations in operational conditions [1].

Current mode control was proposed in [5] to overcome the limitation of voltage mode control. Current mode control employs additional feedback from the resonant tank current to alleviate the dependency of the converter dynamics on operational conditions. The superiority of current mode

Manuscript received Jul. 11, 2013; revised Nov. 8, 2013

Recommended for publication by Associate Editor Yan Xing.

†Corresponding Author: bchoi@ee.knu.ac.kr

Tel: +82-53-950-6603, Fax: +82-53-950-5505, Kyungpook Nat'1 University

*Department of Electronics Engineering, Hanyang University, Korea

${ }^{* *}$ LG Electronics, Korea

${ }^{* * *}$ School of Electronics Engineering, Kyungpook Nat'l University, Korea

${ }^{* * * *}$ Department of Electronics Engineering, Cheongju University, Korea control over conventional voltage mode control was effectively verified in a previous publication [5].

The resonant tank current used as the source of the current feedback signal is a sinusoidal $\mathrm{AC}$ waveform that should be adequately filtered before being utilized as the final current feedback signal. The original current mode control [5] employed a simple rectification circuit as the current sensing network (CSN) and a constant gain amplifier as the current feedback circuit. Although the rectification circuit can provide some filtering, the current feedback signal still contains an $\mathrm{AC}$ component. The under-filtered $\mathrm{AC}$ component could destabilize or saturate the output of the voltage-controlled oscillator (VCO) and jeopardize the frequency modulation control for LLC series resonant converters.

An average current mode control scheme is proposed in this paper to resolve the aforementioned problem of the original current mode control. In the proposed control scheme, the constant gain amplifier in the original current mode control is replaced with an integrator-type compensation amplifier to provide sufficient filtering and boost the gain of the current feedback circuit. The integrator-type compensation amplifier practically eliminates the $\mathrm{AC}$ 


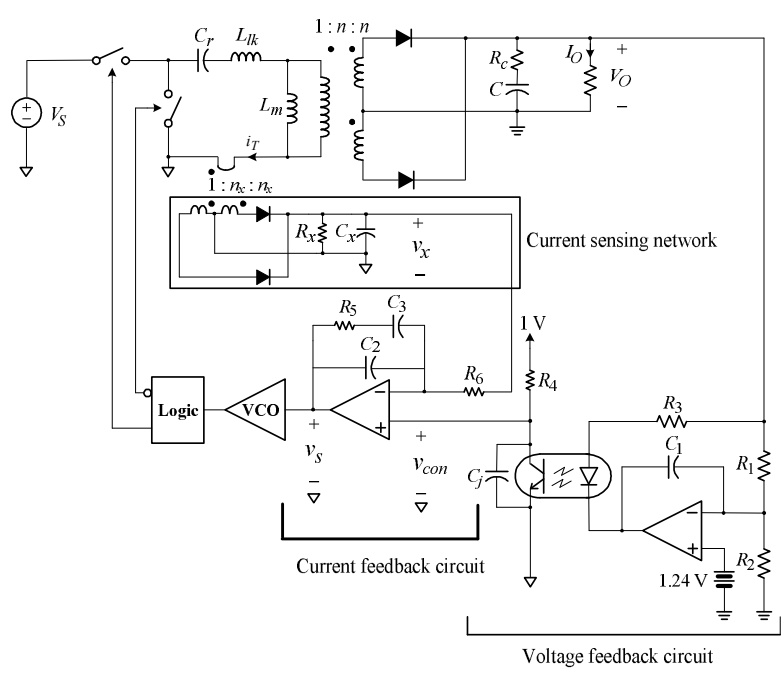

Fig. 1. Experimental LLC resonant converter with the proposed average current mode control, where $V_{S}=340-390 \mathrm{~V}$, $V_{O}=24 \mathrm{~V}, I_{O}=1-6 \mathrm{~A}, C_{r}=47 \mathrm{nF}, \quad L_{l k}=160 \mu \mathrm{H}$, $L_{m}=1.24 \mathrm{mH}, n=0.14, C=2 \mathrm{mF}, R_{c}=5 \mathrm{~m} \Omega, n_{x}=100$, $R_{x}=50 \Omega \quad, \quad C_{x}=0.1 \mu \mathrm{F} \quad, \quad R_{1}=2.2 \mathrm{k} \Omega \quad, \quad R_{2}=120 \Omega$, $R_{3}=300 \Omega \quad, R_{4}=620 \Omega, R_{5}=2.2 \mathrm{k} \Omega \quad, R_{6}=5.1 \mathrm{k} \Omega$, $C_{1}=0.22 \mu \mathrm{F}, C_{2}=3.2 \mathrm{nF}, C_{3}=0.9 \mu \mathrm{F} \quad$, and $C_{j}=9 \mathrm{nF}$ (optocoupler parasitic capacitance).

component from the current feedback signal. Accordingly, the proposed control scheme retains or improves the performance of the original current mode control while greatly enhancing the noise immunity and reliability of frequency modulation control through VCO.

The principles of average current mode control are presented in this study, with focus on the benefits of tank current feedback. The current feedback signal in the proposed control scheme is compared with that of the original current mode control to highlight the filtering capacity of the integrated compensation amplifier. The design of the average current mode control scheme is then discussed. Guidelines for selecting the parameters of the current and voltage feedback circuits are also provided. Lastly, the performance of the proposed average current mode control scheme is demonstrated with an experimental $150 \mathrm{~W}$ LLC converter operating with a wide input voltage variation.

\section{SMALL-SIGNAL DYNAMICS AND BENEFITS OF AVERAGE CURRENT MODE CONTROL}

Fig. 1 shows the circuit diagram of the experimental LLC converter that employs the proposed average current mode control scheme. As in the typical case of offline power supplies, the input voltage varies between $340 \mathrm{~V}<V_{S}<390 \mathrm{~V}$. The converter provides $24 \mathrm{~V}$ output voltage at $6 \mathrm{~A}$ load current. The voltage feedback circuit is implemented with an op amp and photocoupler along with
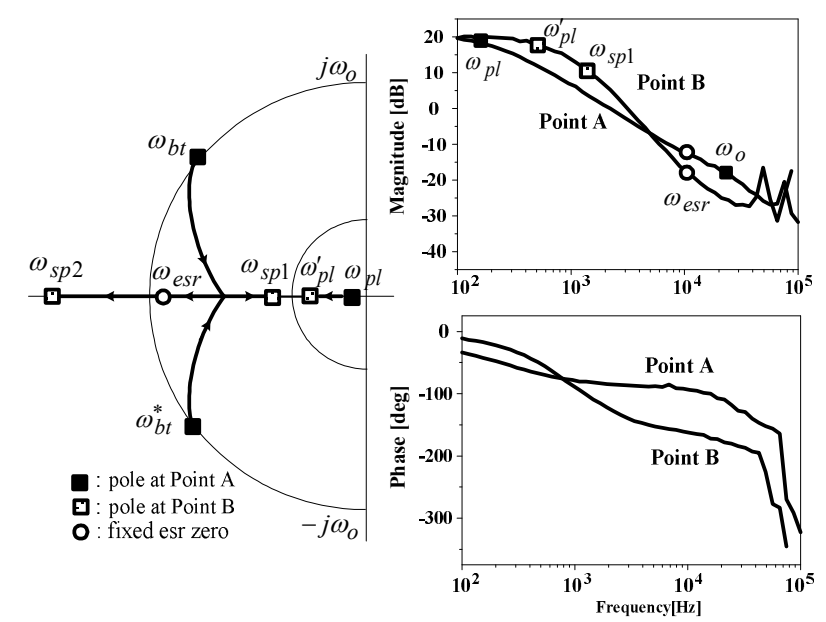

(a)

(b)

Fig. 2. Control-to-output transfer functions without current feedback. (a) Pole/zero trajectory. (b) Bode plot.

other passive components. The current feedback signal is fed from the tank current by the current sensing network (CSN) and current feedback circuit. A center-tapped transformer rectification circuit is utilized for CSN. The current feedback circuit is designed as an integrator-type compensation amplifier for both large ripple attenuation and high feedback gain.

\section{A. Control-to-Output Transfer Function without Current Feedback}

Previous studies [1-4] have proven that the small-signal dynamics of LLC converters vary substantially when operational conditions are changed. The major result of these analyses is shown in Fig. 2 in conjunction with the dynamic characteristics of the experimental LLC converter in Fig. 1.

Fig. 2 shows the converter dynamics when tank current feedback is not employed. Fig. 2(a) illustrates the pole/zero trajectory of the control-to-output transfer function, given by the product of the frequency-to-output transfer function and the gain of the VCO circuit, with respect to the input voltage variation. The trajectory reveals the locations of the poles and zeros, as the input voltage decreases from the maximum value (represented by operating point A with $V_{S}=390 \mathrm{~V}$ ) to the minimum value (denoted as point B with $V_{S}=340 \mathrm{~V}$ ).

At point $\mathrm{A}$, the transfer function has a complex pole pair, $\omega_{b t}$ and $\omega_{b t}^{*}$, which originated from beat-frequency dynamics [3], and a low-frequency pole, $\omega_{p l}$, that stemmed from the output filter capacitor and load resistor. The transfer function also has a fixed ESR zero, $\omega_{e s r}$. As the operating point moves from point $\mathrm{A}$ to point $\mathrm{B}$, the complex pole pair, $\omega_{b t}$ and $\omega_{b t}^{*}$, splits into two real poles, $\omega_{s p 1}$ and $\omega_{s p 2}$. The low-frequency pole shifts toward higher frequencies from $\omega_{p l}$ to $\omega_{p l}^{\prime}$. As illustrated in Fig. 2(a), $\omega_{s p 2}$ passes $\omega_{e s r}$ and moves to 


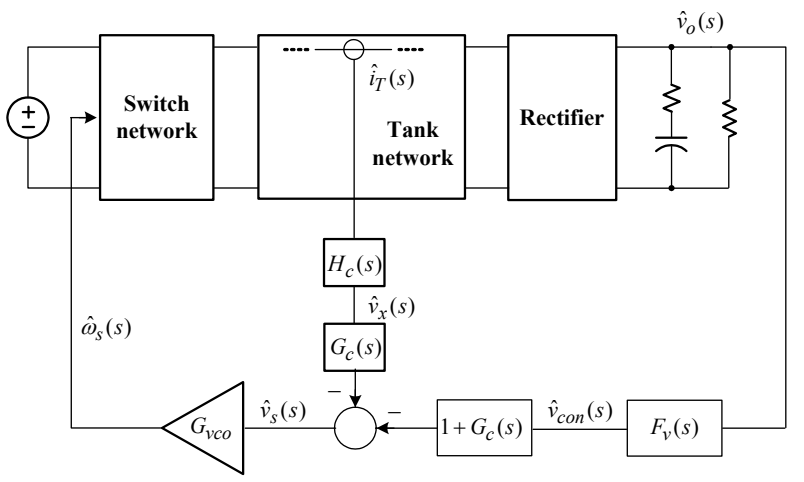

Fig. 3. Small-signal block diagram of an LLC converter with average current mode control.

higher frequencies. $\omega_{s p 1}$ shifts toward lower frequencies and approaches $\omega_{p l}^{\prime}$.

The control-to-output transfer function of the experimental converter without the current feedback is investigated to validate the predictions from Fig. 2(a). For this analysis, the time-domain simulation method proposed in [1] and [3] is used to investigate the frequency response of the transfer function. As shown in Fig. 2(b), the converter exhibits notable changes in the control-to-output transfer function at operating points A and $\mathrm{B}$ in the exact manner predicted in the pole/zero trajectory of Fig. 2(a).

When the control-to-output transfer function shown in Fig. 2(b) is used as the feedback signal similar to the case of conventional voltage mode control, the performance of the converter is directly influenced by operational conditions [1]. The average current mode control could make the control-to-output transfer largely invariant to the changes in operational conditions as demonstrated in the succeeding section. This condition enables the controller to be designed in such a manner that good closed-loop performance is consistently exhibited for all operational conditions.

\section{B. Control-to-Output Transfer Function with Current Feedback}

Fig. 3 shows a functional small-signal block diagram of the LLC converter with the proposed average current mode control. The definitions and expressions of the gain blocks in Fig. 3 are summarized in Table 1. The control-to-output transfer function, $\hat{v}_{o}(s) / \hat{v}_{c o n}(s)$, at the presence of the tank current feedback is evaluated as

$$
\left.\frac{\hat{v}_{o}(s)}{\hat{v}_{c o n}(s)}\right|_{\text {current feeback }} \equiv G_{v c i}(s)=\frac{\left(1+G_{c}(s)\right) G_{v c o} \frac{\hat{v}_{o}(s)}{\hat{\omega}_{s}(s)}}{1+G_{c}(s) G_{v c o} H_{c}(s) \frac{\hat{i}_{T}(s)}{\hat{\omega}_{s}(s)}}(1)
$$

where $\hat{v}_{o}(s) / \hat{\omega}_{s}(s)$ is the frequency-to-output transfer function, and $\hat{i}_{T}(s) / \hat{\omega}_{s}(s)$ denotes the frequency-to-tank current transfer function. Expression (1) is approximated to
TABLE I

EXPRESSIONS FOR GAIN BLOCKS IN FIG. 3

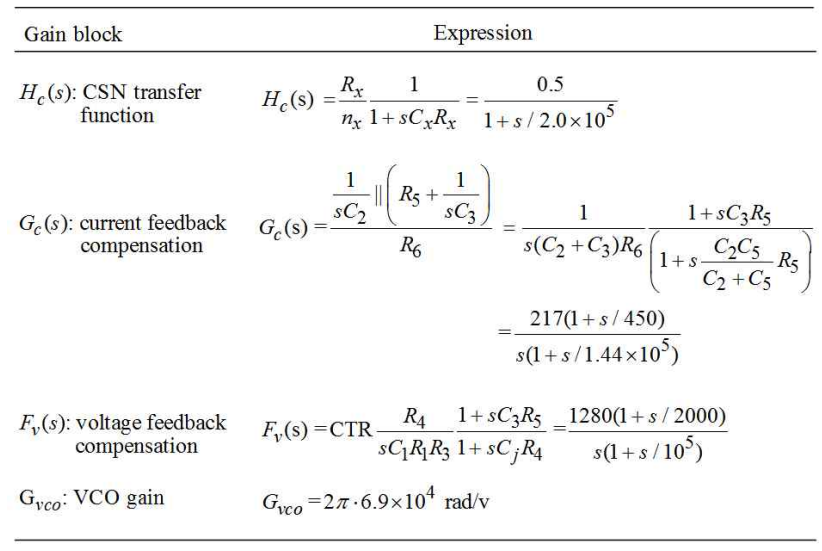

$$
G_{v c i}(s) \approx \frac{G_{c}(s) G_{v c o} \frac{\hat{v}_{o}(s)}{\hat{\omega}_{s}(s)}}{G_{c}(s) G_{v c o} H_{c}(s) \frac{\hat{i}_{T}(s)}{\hat{\omega}_{s}(s)}}=\frac{\frac{\hat{v}_{o}(s)}{\hat{\omega}_{s}(s)}}{H_{c}(s) \frac{\hat{i}_{T}(s)}{\hat{\omega}_{s}(s)}}
$$

with the assumptions $\left|G_{c}(j \omega)\right| \gg 1$ and

$G_{v c o}\left|G_{c}(j \omega)\right| \cdot\left|H_{c}(j \omega)\right| \cdot\left|\hat{i}_{T}(j \omega) / \hat{\omega}_{s}(j \omega)\right| \gg 1$, which hold true for the frequency range of practical importance. The benefits of current feedback are inferred from Expression (2) as follows.

1) Any drift in the power stage dynamics caused by the changes in operational conditions will commonly propagate to all the power stage transfer functions.

2) The consequential effects of drift on transfer functions $\hat{v}_{o}(s) / \hat{\omega}_{s}(s)$ and $\hat{i}_{T}(s) / \hat{\omega}_{s}(s)$ will be the same and will thus be cancelled by each other. Accordingly, the control-to-output transfer function with the current loop closed, $G_{v c i}(s)$, will remain the same.

Fig. 4 shows the evaluation of the control-to-output transfer function, $G_{v c i}(s)$, of the experimental converter. Fig. 4(a) provides a conceptual representation of the PSIM model [8] used in this analysis.

The complete PSIM model for $G_{v c i}(s)$ evaluation is shown in the Appendix. The analysis results are shown in Fig. 4(b) along with the experimental measurements. The transfer function shows consistent characteristics over a wide frequency range.

The benefits of tank current feedback become obvious when Fig. 4(b) is compared with Fig. 2(b), which shows the control-to-output transfer function without the current feedback. With tank current feedback, the control-to-output transfer function remains mostly unchanged. Voltage feedback compensation can thus be designed for desired closed-loop performance for the entire operational range.

C. Comparison with Conventional Current Mode Control 


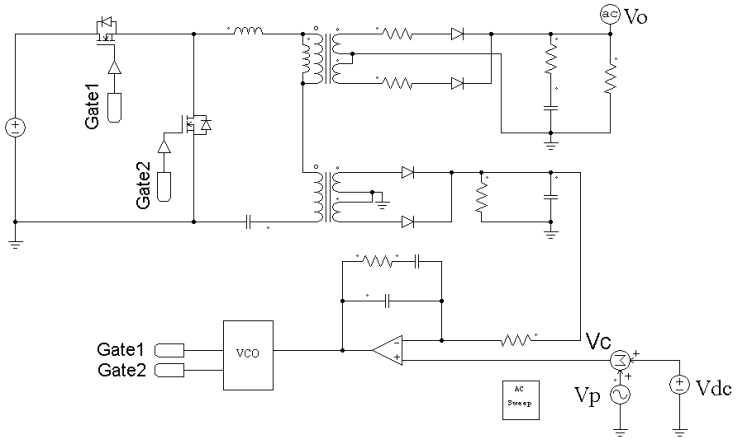

(a)

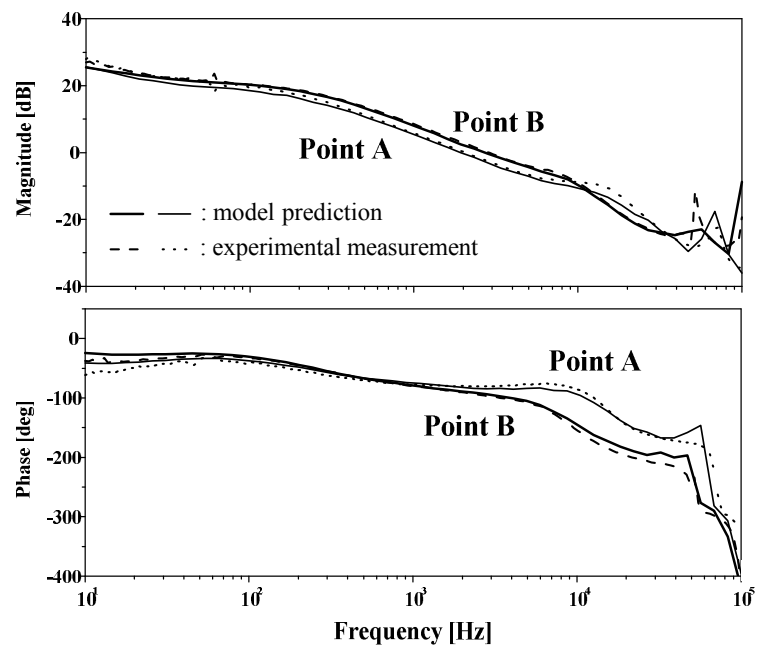

(b)

Fig. 4. Evaluation of the control-to-output transfer function with current feedback. (a) Conceptual PSIM model for the time-domain simulation method. (b) Control-to-output transfer function with current feedback. The experimental measurements are obtained with a PSM1735 impedance analyzer.

The distinguishing merit of the new average current mode control becomes evident when the control scheme is compared with the original current mode control [5]. Fig. 5(a) shows the structures of the CSN and current feedback circuit of the two control schemes. The original current mode control shown at the top of Fig. 5(a) employs a constant gain amplifier. By contrast, the average current mode control at the bottom of Fig. 5(a) employs an integrating amplifier with a two-pole, one-zero compensation structure.

Fig. 5(b) shows the output signal from CSN, $v_{x}$, and the input signal to VCO, $v_{s}$, for the two control schemes at the same operational condition of $V_{S}=390 \mathrm{~V}$ and $I_{O}=6 \mathrm{~A}$. The maximum value for the VCO input is limited to $v_{s \max }=2.5 \mathrm{~V}$. The CSN output exhibits a $0.45 \mathrm{~V}$ sinusoidal variation. For the original current mode control, the ripple component in $v_{x}$ is directly transmitted to $v_{s}$ without any attenuation. The large ripple component could destabilize the output of VCO. With a large ripple component, the peak value of $v_{s}$ also approaches the upper limit of $v_{s \max }=2.5 \mathrm{~V}$, thereby endangering the $\mathrm{VCO}$ operation.
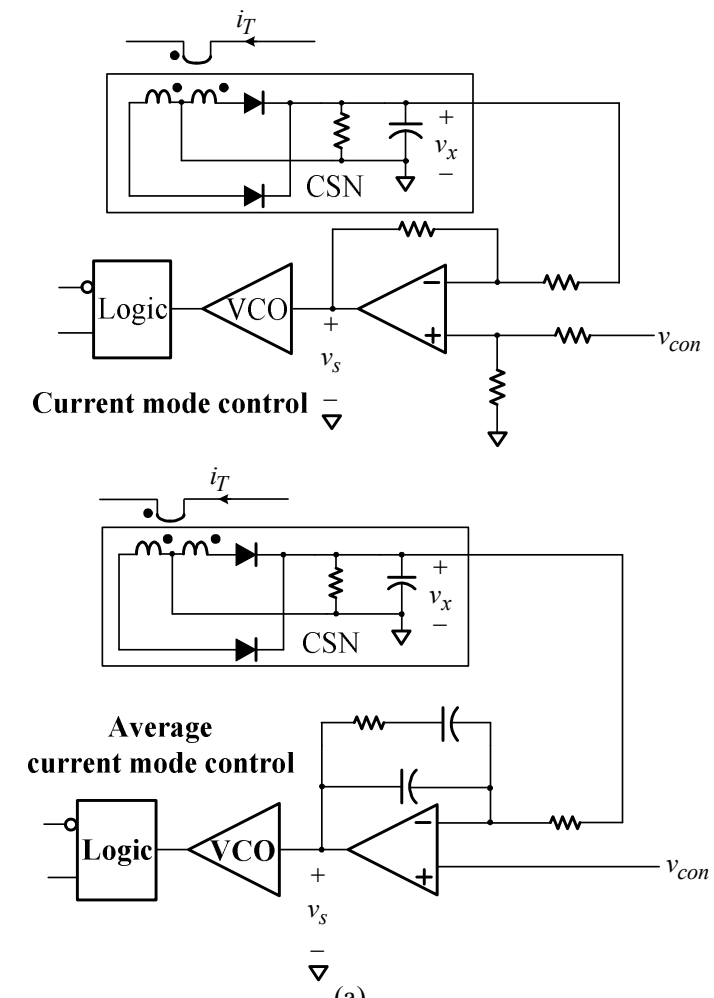

(a)
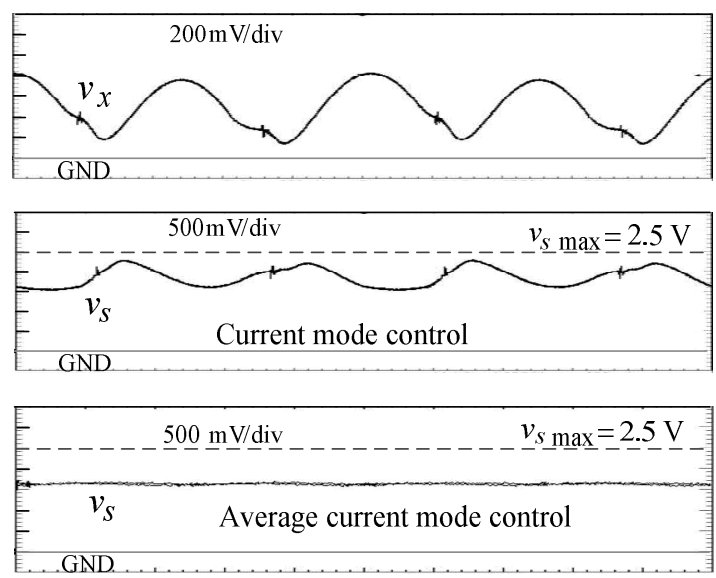

(b)

Fig. 5. Comparison with conventional current mode control. (a) Current feedback circuit. (b) CSN output signal and VCO input signal.

For the average current mode control, the integrating amplifier sufficiently reduces the ripple component and provides a nearly constant VCO input signal with a safe margin against $v_{s \max }=2.5 \mathrm{~V}$.

\section{Design Of THE AVERAge CURRENT Mode CONTROL}

The implementation of the proposed average current mode control requires the design of the CSN, current feedback compensation, and voltage feedback compensation. 


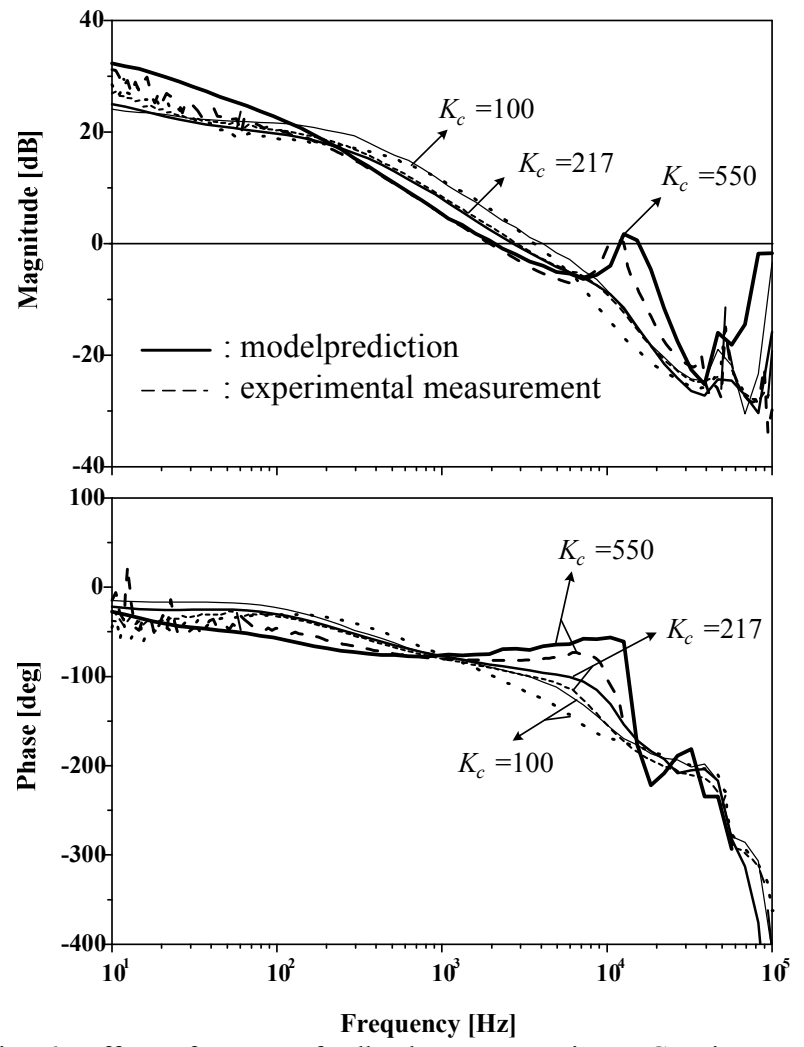

Fig. 6. Effect of current feedback compensation DC gain $K_{c}$ on the control-to-output transfer function. The experimental measurements obtained with a PSM1735 impedance analyzer.

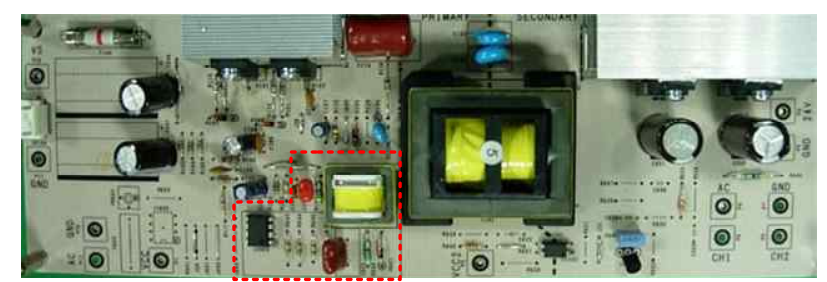

Fig. 7. Experimental converter. The control circuit for the average control is highlighted with a dashed box.

\section{A. Current Feedback Compensation Design}

CSN design has already been discussed in a previous publication [5]. This section thus covers the design of current feedback compensation. The two-pole, one-zero structure is selected for the current compensation design as follows:

$$
G_{c}(s)=\frac{K_{c}\left(1+\frac{s}{\omega_{z c}}\right)}{s\left(1+\frac{s}{\omega_{p c}}\right)} .
$$

to provide the desired filtering characteristics without causing excessive phase delay to the current feedback circuit.

The current feedback compensation parameters can be selected in consideration of the $G_{v c i}(s)$ characteristics and filtering of the AC component from $v_{x}$.

- Compensation zero $\left(\omega_{z c}\right)$ is placed at sufficiently low frequencies, typically below $2 \pi \cdot 100 \mathrm{r} / \mathrm{s}$, so that the low-frequency phase of $G_{v c i}(s)$ remains at $-45^{\circ}<\angle G_{v c i}<0^{\circ}$.

- Compensation pole $\omega_{p c}$ is placed at half the minimum switching frequency, which occurs at operating point B with $V_{S}=340 \mathrm{~V}$.

- Integrator gain $K_{c}$ is adjusted to increase the crossover frequency of $G_{v c i}(s)$ without degrading the high-frequency characteristics.

The above recommendations can be used as general guidelines, and the exact compensation parameters can be fine-tuned by investigating the $G_{v c i}(s)$ characteristics. For the experimental converter, the corner frequencies of current feedback compensation are selected as $\omega_{z c}=2 \pi \cdot 72 \mathrm{r} / \mathrm{s}$ and $\omega_{p c}=2 \pi \cdot 23 \times 10^{3} \mathrm{r} / \mathrm{s}$ based on the above guidelines. With the preselected corner frequencies, the $G_{v c i}(s)$ characteristics are analyzed with different values for integrator gain $K_{c}$.

Fig. 6 shows the Bode plots of $G_{v c i}(s)$ obtained from the time-domain simulation method at point $B$ with the three integrator gains of $K_{c}=100, K_{c}=217$, and $K_{c}=550$. Fig. 6 indicates that a large $K_{c}$ improves the mid-frequency phase characteristics. However, with the largest integrator gain $K_{c}=550$, the control-to-output transfer function exhibits peaking after the $0 \mathrm{~dB}$ crossover. This peaking could destabilize the current feedback circuit and trigger a high-frequency oscillation. Analyzing this trade-off, $K_{c}=217$ is selected for the integrator gain, and the final designs of $\omega_{z c}=2 \pi \cdot 72 \mathrm{r} / \mathrm{s}, \omega_{p c}=2 \pi \cdot 23 \times 10^{3} \mathrm{r} / \mathrm{s}$, and $K_{c}=217$ are obtained.

\section{B. Voltage Feedback Compensation Design}

For the voltage feedback circuit design, finding an exact expression for the control-to-output transfer function $G_{v c i}(s)$ evaluated at the presence of tank current feedback may be necessary. However, this task is too challenging because of complex power stage dynamics. As an alternative engineering practice, $G_{v c i}(s)$ can be approximated as a third-order polynomial based on the profile of the Bode plots shown in Fig. 6 [5]. Thus,

$$
G_{v c i}(s) \approx K_{v c i} \frac{1+\frac{s}{\omega_{e s r}}}{\left(1+\frac{s}{\omega_{l w}}\right)\left(1+\frac{s}{Q \omega_{n}}+\frac{s^{2}}{\omega_{n}^{2}}\right)} .
$$

Zero frequency $\omega_{\text {esr }}=1 /\left(C R_{c}\right)$ is determined by the ESR and capacitance of the output filter capacitor. The 

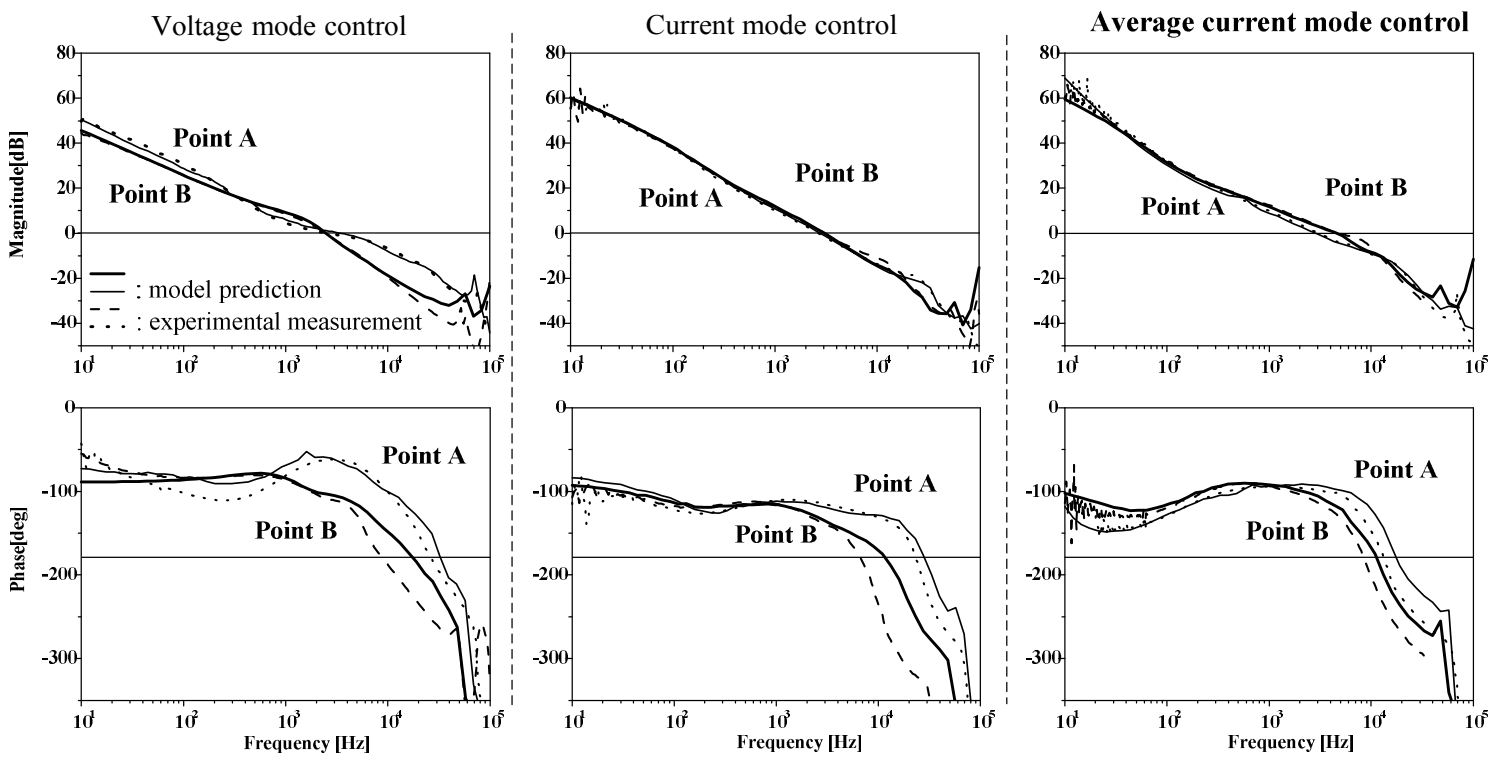

(a)

Voltage mode control

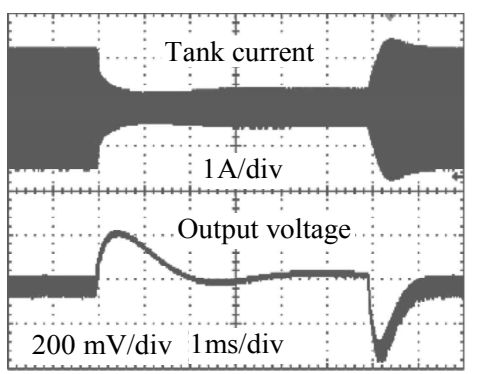

Current mode control

Average current mode control
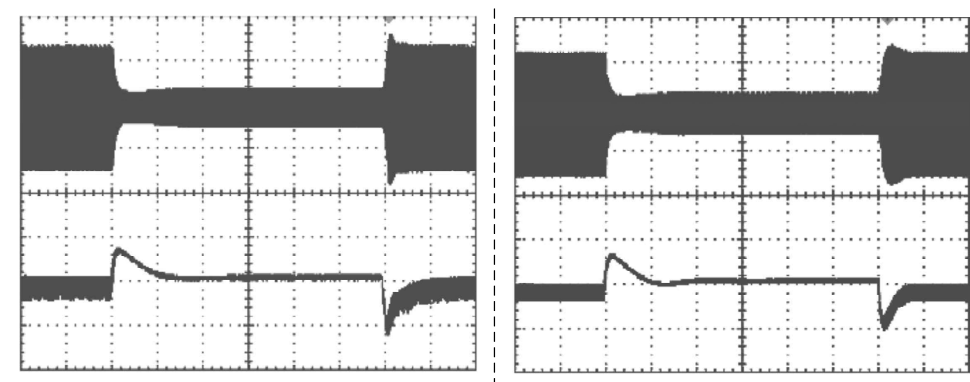

(b)

Fig. 8. Performance evaluation for the average current mode control. (a) Loop gain characteristics. (b) Step load response. The experimental measurements are obtained with a PSM1735 impedance analyzer.

low-frequency frequency pole $\omega_{l w}$ is inversely proportional to the product of output capacitance and load resistance. From the Bode plots in Figs. 4(b) and 6, the location of this pole is approximated as $\omega_{l w} \approx 2 \pi \cdot 250 \mathrm{r} / \mathrm{s}$. The quadratic term in the denominator originated from the beat-frequency dynamics of the converter [1-3]. For the given control-to-output transfer function structure, a two-pole, one-zero voltage feedback compensation

$$
F_{v}(s)=\frac{K_{v}\left(1+\frac{s}{\omega_{z v}}\right)}{s\left(1+\frac{s}{\omega_{p v}}\right)}
$$

provides good loop gain characteristics.

The selection procedures for the compensation parameters are provided below.

- Compensation pole $\omega_{p v}$ is placed at $\omega_{e s r}$ of the control-to-output transfer function $G_{v c i}(s)$.
- Compensation zero $\omega_{z v}$ is placed at the low-frequency pole $\omega_{l w}$ of $G_{v c i}(s)$.

- Integrator gain $K_{v}$ is adjusted to place the crossover frequency of the loop gain, $T(s)=G_{v c i}(s) F_{v}(s)$, at high frequencies while securing a sufficient phase margin.

The above design procedures yield a loop gain that maintains the $-20 \mathrm{~dB} / \mathrm{dec}$ magnitude slope until the mid-frequencies.

For the experimental converter, voltage feedback compensation is designed as $\omega_{z v}=2 \pi \cdot 318 \mathrm{r} / \mathrm{s}$, $\omega_{p v}=2 \pi \cdot 1.59 \times 10^{4} \mathrm{r} / \mathrm{s}$, and $K_{v}=1.28 \times 10^{3}$. The loop gain characteristics with this voltage feedback compensation are evaluated in the succeeding section.

\section{PERFormance OF THE AVERAGE CURRENT MODE CONTROL}

The experimental LLC converter with the proposed 
average current mode control is shown in Fig. 7. The performance of the average current mode control is compared with that of other existing control schemes. The average current mode control outperforms the voltage mode control and compares favorably with the original current mode control.

\section{A. Loop Gain Characteristics}

Fig. 8(a) shows the loop gain characteristics of the experimental converter with the proposed average current mode control together with the cases of the conventional voltage mode control [1] and the original current mode control [5]. The PSIM model used in this loop gain analysis is shown in the Appendix.

For the conventional voltage mode control, the loop gain characteristics vary notably at points A and B. By contrast, the average current mode control consistently provides good loop gain characteristics as in the case of the original current mode control. At point B, the average current mode control shows superior loop gain characteristics over current mode control, with a higher crossover frequency and larger phase margin. This result confirms that the proposed average current mode control can enhance the performance of the original current mode control with much improved noise immunity and reliability as demonstrated in Fig. 5.

\section{B. $\quad$ Step Load Transient Response}

Fig. 8(b) provides a comparison of the measured tank current and output voltage of the experimental converter in response to the step changes in the load current, $I_{O}=1 \mathrm{~A} \Rightarrow 6 \mathrm{~A} \Rightarrow 1 \mathrm{~A}$, at operating point A. Although the three control schemes all show stable and well-controlled behavior, noticeable differences are observed in the speed and transient behavior of output voltage. Average current mode control outperforms voltage mode control by exhibiting a faster response and smaller overshoot/undershoot and compares favorably with current mode control.

\section{CONCLUSIONS}

An average current mode control scheme that overcomes the limitations of both voltage mode control and current mode control was developed in this study. The proposed average current mode control scheme employs an integrator-type compensation amplifier in the current feedback circuit to improve the performance of the existing control schemes while enhancing the noise immunity and reliability of the controller.

Design guidelines for current feedback and voltage feedback compensation were provided. The performance of the average current mode control was verified both theoretically and experimentally with an experimental 150 W LLC series resonant DC-to-DC converter.

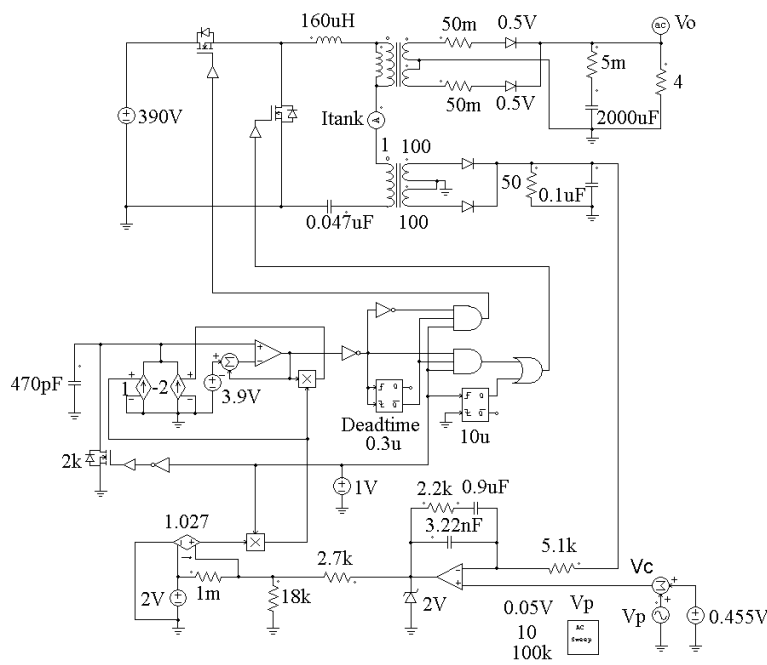

(a)

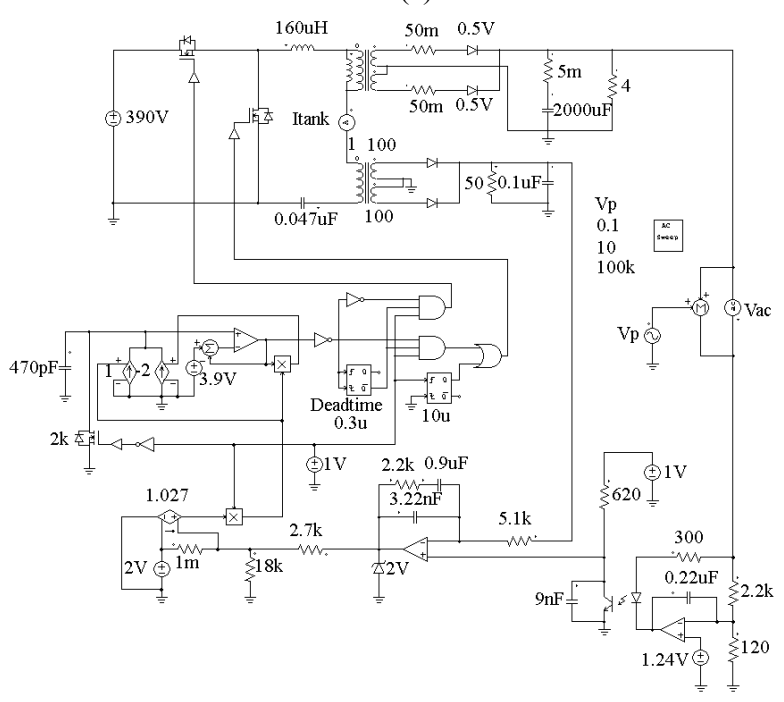

(b)

Fig. 9. PSIM models for the time-domain simulation method. (a) PSIM model for the control-to-output transfer function analysis. (b) PSIM model for the loop gain analysis.

The proposed average current mode control outperforms voltage mode control and can improve the performance of the original current mode control.

\section{APPENDIX}

Fig. 9 shows the PSIM models for the time-domain simulation method. These models were used to analyze the control-to-output transfer function and loop gain of the experimental LLC converter.

\section{ACKNOWLEDGMENTS}

This research was supported by the Ministry of Science, ICT, and Future Planning, Korea, under the Information Technology Research Center support program 
(NIPA-2013-H0301-13-1001) supervised by the National IT Industry Promotion Agency.

\section{REFERENCES}

[1] J. Jang, M. Joung, B. Choi, S. Hong, and S. Lee, "Dynamic analysis and control design of optocoupler-isolated LLC series resonant converters with wide input and load variations," IET Power Electron., Vol. 5, pp. 755-764, Jun. 2012.

[2] B. Yang, "Topology investigation for frontend DC/DC power conversion for distributed power systems," $\mathrm{Ph}$. D. dissertation, Virginia Polytechnic Institute and State University, Blacksburg, VA, 2003.

[3] B. Yang and F. C. Lee, "Small-signal analysis for LLC resonant converter," CPES Seminar, S 7.3, pp. 144-149, 2003.

[4] E. X. Yang, "Extended describing function method for small signal modelling of resonant and multi resonant converters," Ph. D. dissertation, Virginia Polytechnic Institute and State University, Blacksburg, VA, 1994.

[5] J. Jang, M. Joung, S. Choi, Y. Choi, and Byungcho Choi, "Current mode control for LLC series resonant dc-to-dc converters," IEEE Applied Power Electronics Conf., pp. 21-27, Mar. 2011.

[6] B. Reza, R. Bizhan, R. Z. Mohammad, and M. H. Seyed, "Using LLC resonant converter for designing wide-range voltage source," IEEE Trans. Ind. Electron., Vol. 58, No. 5, pp. 1746-1756, May 2011.

[7] M. P. Foster, C. R. Gould, A. J. Gilbert, D. A. Stone, and C. M. Bingham, "Analysis of CLL voltage-output resonant converters using describing functions," IEEE Trans. Power Electron., Vol. 23, No. 4, pp. 1772-1780, Jul. 2008.

[8] "PSIM User's Guide," Powersim Inc, Version 9.0, May 2010.

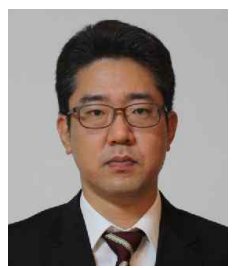

Chang Hee Park received his B.S. degree in electronics engineering from Hanyang University, Korea, in 2000 and his M.S. degree in electronics engineering from Yonsei University, Korea, in 2005. He has been working at Korea Spectral Products as the Director of its R\&D Center since 2004. $\mathrm{He}$ is currently a Ph.D. candidate at the Department of Electronics and Computer Engineering at Hanyang University, Seoul, Korea. His research interests include power electronics, control systems, and efficient energy design.

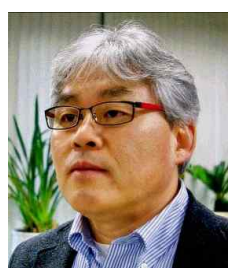

Sung Ho Cho received his Ph.D. degree in electrical and computer engineering from the University of Utah, Salt Lake City, USA, in 1989. He worked with the Electronics and Telecommunications Research Institute in Daejon, Korea, as a member of the technical staff from 1989 to 1992 . Since 1992, he has been with the School of Electronics Engineering at Hanyang University, Seoul, Korea, where he is now a professor. His research interests include wireless power transfer systems, analog-digital co-design, and signal processing for sensors.

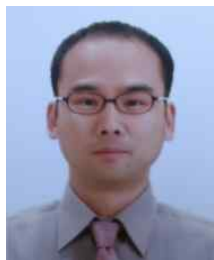

Jinhaeng Jang received his B.S. degree in electronics from Kumoh National Institute of Technology, Gumi, Korea, in 2000 and his M.S. and Ph.D. degrees in circuits and embedded systems engineering from Kyungpook National University, Taegu, Korea, in 2009 and 2013, respectively. He is currently with the Power Team, LG Electronics, Pyeongtaek, Kyunggi-Do, Korea. His research interests include dynamic analysis and control design of AC-to-DC and DC-to-DC power converters for consumer electronics.

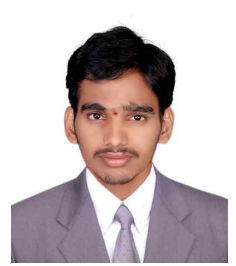

Syam Kumar Pidaparthy received his B. Tech. degree in electrical and electronics engineering from Acharya Nagarjuna University, Guntur, India, in 2010 and his M.S. degree in circuits and embedded systems engineering from Kyungpook National University, Taegu, Korea, in 2013. His research interests include modeling, dynamic analysis, and control design of DC-to-DC power converters for consumer electronics.

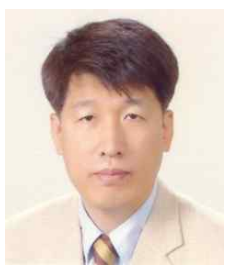

Taeyoung Ahn received his B.S. degree in electronics engineering and his M.S. degree in electrical engineering from Hanyang University, Seoul, Korea, in 1984 and 1990, respectively. He obtained his $\mathrm{Ph} . \mathrm{D}$. degree in electronics engineering from Kyushu University, Kyushu, Japan, in 1994. In 1997, he joined the Department of Electronics Engineering, Cheongju University, Cheongju, Korea, where he is currently a professor. His main research interests include analysis and design optimization of high-efficiency switching power converters.

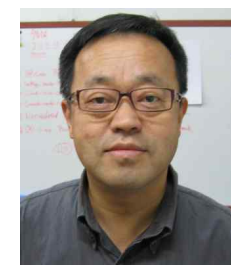

Byungcho Choi (S'90-M'91) received his B.S degree in electronics from Hanyang University, Seoul, Korea, in 1980 and his M.S. and Ph.D. degrees in electrical engineering from Virginia Polytechnic Institute and State University, Blacksburg, Virginia, in 1988 and 1992, respectively. In 1996, he joined the School of Electrical Engineering and Computer Science, Kyungpook National University, Taegu, Korea, where he is presently a professor. His research interests include modeling and design optimization of high-frequency power converters for portable electronics, computer power systems, and distributed power systems. He is the author of the book "Pulsewidth Modulated Dc-to-Dc Power Conversion," Wiley, New Jersey, 2013. 